\title{
ARTIGOS
}

Submetido em 29.11.2012. Aprovado em 18.3.2014

Avaliado pelo sistema double blind review. Editor Científico: Kleber Fossati Figueiredo

http://dx.doi.org/10.1590/So034-759020140408

\section{IMERSÃO SOCIAL NA CADEIA DE SUPRIMENTOS E SEU EFEITO PARADOXAL NO DESEMPENHO OPERACIONAL}

\author{
Social embeddedness in supply chain and its paradoxical impact on \\ operation performance
}

\author{
Inmersión social en la cadena de suministros y su efecto paradójico en el \\ desempeño operativo
}

\section{RESUMO}

Este artigo buscou analisar os efeitos da imersão relacional e da imersão estrutural no desempenho operacional das firmas, medido em termos de ganhos de produtividade e de qualidade. 0 objeto de estudo foi a indústria moveleira, com base em seus laços com clientes e fornecedores. Especificamente, analisamos como a imersão relacional - confiança e solidariedade - reforça a imersão estrutural, que foi avaliada a partir do grau de concentração de fornecedores e clientes das firmas. Foi possível identificar que a imersão relacional teve efeitos positivos nos indicadores de desempenho operacional, porém de maneira distinta: ela afeta a qualidade nas relações com clientes e a produtividade nos laços com fornecedores. Identificamos ainda, dois efeitos paradoxais. No primeiro, níveis baixos de imersão relacional com fornecedores geram efeitos negativos da imersão estrutural na produtividade, mas, em níveis mais altos, esses efeitos são positivos. No segundo, a contradição reside no efeito positivo da combinação dos dois tipos de imersão na produtividade, mas negativo na qualidade.

\section{LUCIANO ROSSONI}

Irossoni@gmail.com

Professor do Programa de Pós-

Graduação em Administração da

Universidade do Grande Rio, Rio

de Janeiro, RJ - Brasil. Pesquisador

Associado do Instituto Brasileiro

de Estudos e Pesquisas Sociais,

Curitiba, $P R$ - Brasil.

\section{GUILHERME SILVEIRA MARTINS \\ guilhermesm2@insper.edu.br \\ Professor do Instituto de Ensino e \\ Pesquisa, São Paulo, SP - Brasil}

\section{RICARDO SILVEIRA MARTINS}

ricardo.s.martins@uol.com.br Professor do Centro de PósGraduação e Pesquisa em Administração da Universidade Federal de Minas Gerais, Belo Horizonte, MG - Brasil.

\section{REBECCA IMPELIZIERI MOURA DA SILVEIRA}

rebeccasilveira@yahoo.com.br Doutoranda em Administração pelo Centro de Pós-Graduação e Pesquisa em Administração da Universidade Federal de Minas Gerais, Belo Horizonte, MG - Brasil
PALAVRAS-CHAVE | Cadeia de suprimentos, desempenho operacional, imersão social, relações interorganizacionais, redes verticais.

\begin{abstract}
This paper aims to analyze structural and relational embeddedness effects in operational performance in terms of productivity and quality gains. We investigated furniture companies and its customers and suppliers ties. Specifically, we analyze how relational embeddedness - trust and solidarity - reinforces structural embeddedness, which was evaluated from outsourcing costs and sales concentration. Our results point out that customers' relational embeddedness improves quality performance, whereas with suppliers leads to productivity gains. We found two paradoxical effects. First, lower levels of trust and solidarity generates negative effect on suppliers of structural embeddedness in productivity, but at higher levels these effects are positive. Second, the contradiction can be observed when we found a
\end{abstract} positive effect of two types of immersion combination in productivity, but negative on quality.

KEYWORDS / Supply chain, operation performance, social embeddedness, inter-organizational relations, vertical networks.

\section{RESUMEN}

Este artículo buscó analizar los efectos de la inmersión relacional y de la inmersión estructural en el desempeño operativo de las firmas, medido en términos de aumentos de productividad y de calidad. El objeto de estudio fue la industria del mueble, con base en sus lazos con clientes y proveedores. Específicamente, se analizó cómo la inmersión relacional - confianza y solidaridad - refuerza la inmersión estructural, que fue evaluada a partir del grado de concentración de proveedores y clientes de las firmas. Fue posible identificar que la inmersión relacional tuvo efectos positivos en los indicadores de desempeño operativo, aunque de manera distinta: ella afecta la calidad en las relaciones con clientes y la productividad en los lazos con proveedores. También fueron identificados dos efectos paradójicos. En el primero, niveles bajos de inmersión relacional con proveedores generan efectos negativos de la inmersión estructural en la productividad, pero, en niveles más altos, esos efectos son positivos. En el segundo, la contradicción reside en el efecto positivo de la combinación de los dos tipos de inmersión en la productividad, pero negativo en la calidad.

PALABRAS CLAVE / Cadena de suministros, desempeño operativo, inmersión social, relaciones interorganizacionales, redes verticales. 


\section{INTRODUÇÃO}

A importância da análise dos relacionamentos desenvolvidos pela firma reside na constatação de que a competitividade emerge não só dos recursos internos que possui, mas também daqueles acessados por ela por intermédio de sua rede de relacionamentos (Dyer \& Singh, 1998; Lavie, 2006). Estudos empíricos buscam verificar a relação positiva entre a adoção de integração de processos, relacionamentos colaborativos, compartilhamento de informações e o desempenho da empresa (Lado, Dant, \& Tekleab, 2008; Lazzarini, 2007). Tais relações são suportadas por várias correntes teóricas, entre elas as Teorias de Custos de Transação (Grover \& Malhotra, 2003; Williamson, 1975), da Dependência de Recursos (Pfeffer \& Salancik, 1978), a Sociologia Econômica (Granovetter, 1985), a Resource -based Theory (Wernerfelt, 1995) e a visão relacional da estratégia (Dyer \& Singh, 1998).

Particularmente, a visão relacional da estratégia mostrou-se como a corrente teórica que elaborou de maneira aprofundada a ideia de que os relacionamentos desenvolvidos pela organização podem configurar-se como importante fonte de vantagem competitiva sustentável. Na visão relacional, há um lucro supernormal ou rendas relacionais que não são gerados pelas organizações individualmente nem em relacionamentos pontuais de mercado, mas, sim, como resultado de uma combinação única de recursos, dispersos nas relações de governança (Dyer \& Singh, 1998).

Essa abordagem vai além das relações de curto prazo (do tipo arm's length) e de contratos formais, ao preconizar que as organizações devem participar de relações intensas de compartilhamento de investimentos, conhecimento e informação, como forma de melhoria de produtos e processos (Lazzarini, Claro, \& Mesquita, 2008). Pesquisadores têm encontrado que, por meio de parcerias, firmas podem beneficiar-se do conhecimento gerado pela relação (Powell, 1996), promovem investimentos específicos da relação sem a necessidade dos altos custos de uma integração vertical (Dyer, 1997) e potencializam o desempenho operacional dos participantes (Lado et al., 2008; Lazzarini, 2007).

Como tais parcerias demandam tempo, esforços e recursos, as firmas participantes tendem a desenvolver esse relacionamento intensamente. Nesse sentido, entender quão imersas as firmas estão nesses relacionamentos torna-se relevante, dado que os laços sociais moldam as expectativas, as motivações e o processo decisório dos agentes em rede (Uzzi \& Gillespie, 1999).

Nesse ensejo, dois tipos básicos de imersão estão presentes nos estudos de redes: estrutural e relacional (Zukin \&
Dimaggio, 1990). A imersão relacional possui uma perspectiva de coesão na rede e ressalta o conteúdo dos laços imediatos da firma no acesso a informação valiosa, tal como o papel da confiança e da solidariedade como mecanismo de governança. Já a imersão estrutural tem uma perspectiva posicional e vai além dos laços imediatos, ao enfatizar como a posição estrutural da firma na rede permite que ela tenha acesso a informação valiosa (Gulati, 1998).

Neste artigo, propomos que o desempenho operacional da firma não é somente resultado da combinação interna de recursos, mas também dos relacionamentos com clientes e fornecedores. Para tanto, o objetivo é analisar os efeitos da imersão relacional e estrutural no desempenho operacional em termos de ganhos de produtividade e qualidade. Como campo de estudo, investigamos 75 indústrias moveleiras, localizadas em quatro arranjos produtivos locais nacionais, e seus respectivos laços com clientes e fornecedores. A pesquisa foi operacionalizada com base na investigação do grau de concentração de fornecedores e clientes das firmas, como medidas da sua imersão estrutural, e do grau de confiança e solidariedade que depositam nesses relacionamentos verticais, como medidas da sua imersão relacional.

Dessa forma, em vez de utilizar medidas que não necessariamente remetem a uma imersão relacional, como frequência, intensidade e tempo de relação (vide, p. ex., Gulati \& Gargiulo, 1999; Rowley, Behrens, \& Krackhardt, 2000; Shipilov, 2005; Uzzi \& Lancaster, 2004), nosso estudo avança no campo da pesquisa em relações interorganizacionais por usar uma avaliação subjetivada das firmas em relação à confiança e solidariedade dos laços, o que é mais coerente com a lógica da imersão social relacional (Granovetter, 1985). Ademais, além de contribuirmos com um indicador de maior conteúdo interpretativo, buscamos avaliar como a imersão relacional e estrutural se reinforçam. Para tanto, neste estudo, damos atenção especial ao efeito da imersão relacional em termos de confiança e solidariedade como moderadora da relação entre imersão estrutural e desempenho operacional. Por fim, fizemos uma avaliação considerando dois tipos de parceiros, clientes e fornecedores, em que avaliamos os efeitos da imersão com esses atores tanto para a qualidade quanto para a produtividade.

O artigo está estruturado em cinco seções, além desta introdutória. Na primeira, é apresentado o quadro teórico-empírico de referência, para depois serem ilustrados os argumentos que suportam as hipóteses do estudo. Na terceira seção, expõem-se os procedimentos metodológicos adotados e, a seguir, os resultados encontrados. Esses resultados são discutidos na última seção do texto, em conjunto com as conclusões do trabalho. 


\section{QUADRO TEÓRICO-EMPÍRICO DE REFERÊNCIA}

0 arcabouço teórico deste trabalho foi construído com base no pressuposto de que os recursos críticos da firma podem ser desenvolvidos além dos seus limites, a partir de sua rede de relacionamentos. A visão relacional da estratégia mostrou-se como a corrente teórica que desenvolveu, de maneira mais aprofundada, a ideia de que os relacionamentos desenvolvidos pela organização podem configurar-se como importante fonte de vantagem competitiva. Seu desenvolvimento teórico é uma extensão da Resource-based View (RBV) e tem raízes em Zajac e Olsen (1993), que propuseram o conceito de valor de transação como ponto de vista alternativo aos custos de transação. Nesse sentido, a definição das estratégias interfirmas deveria considerar os benefícios mútuos entre os parceiros, de modo a retirar o foco exclusivo da análise em cima dos custos de transação para, assim, ampliar o foco do embasamento da decisão para o valor total gerado pela parceria. Os autores preconizam que, no longo prazo, o valor da parceria é amplificado, em função de um aprendizado em conjunto, do desenvolvimento de confiança entre organizações e do melhor gerenciamento de conflitos. Nos termos de Dyer e Singh (1998), a ampliação desse valor está ligado à existência de um lucro supernormal ou rendas relacionais.

A abordagem deste artigo na investigação de relacionamentos interfirmas não só reconhece que os relacionamentos podem ser vistos como recursos, como, adicionalmente, compartilha da ideia de que a estrutura social desempenha um papel significativo no comportamento econômico, combinada com a noção de que a ação econômica está imersa na estrutura social (Granovetter, 1985). Tal imersão (embeddedness) é, na sua essência, um argumento contrário à lógica de abordar relações diádicas e decisões econômicas de maneira isolada, frequentemente retratada pela teoria econômica clássica (Baker, 1990). A lógica da imersão sugere, assim, que os laços sociais moldam as expectativas, as motivações e o processo decisório dos agentes em rede, incorporando aspectos ligados a confiança nas relações como condicionante (Granovetter, 1985; Uzzi \& Gillespie, 1999).

Nesse sentido, é importante considerar como o grau de imersão das firmas na rede atua nos relacionamentos interorganizacionais, seja em adição ou em substituição aos mecanismos de governança formais. Powell (1990) ressalta que a imersão possui papel que vai além dos mecanismos de negociação de preços, na medida em que há existência de controle social que cria incentivos para que os agentes possuam autocontrole sobre seu comportamento.

Dois tipos básicos de imersão estão presentes nos estudos de redes: estrutural e relacional (Zukin \& Dimaggio, 1990).
A imersão relacional possui uma perspectiva de coesão na rede e ressalta o papel dos laços imediatos e da confiança no acesso a informação valiosa. Já a imersão estrutural tem uma perspectiva posicional e vai além dos laços imediatos, ao enfatizar como a posição estrutural da firma no mercado permite que ela tenha acesso a informação valiosa (Gulati, 1998).

Embora central para a discussão dos artigos sobre redes, a diferenciação entre os dois tipos de imersão nem sempre fica clara nos artigos publicados sobre o tema (Rowley et al., 2000). A imersão estrutural está relacionada à densidade dos laços desenvolvidos pela empresa. A estrutura diz respeito, assim, aos canais de comunicação que a firma tem com outras firmas em uma rede. Desse modo, a imersão estrutural combina as condições macroestruturais das trocas econômicas com os microfundamentos da tomada de decisão e comportamento (Uzzi, 1997).

Um foco importante na imersão estrutural é o tipo de relações que ligam os atores. Tais relações são usualmente classificadas em dois tipos: laços de curta distância (arm's length ties) e laços imersos (embedded ties) (North, 1990; Shipilov, 2005; Uzzi, 1997). Laços de curta distância ocorrem de maneira esporádica, sem qualquer contato social prolongado entre as partes, dando a entender que são pautados puramente em necessidades imediatas. Mesmo não havendo obrigações sociais entre os atores econômicos, nesse tipo de troca, a governança da relação está baseada em regras explícitas e claras, necessárias para reduzir a incerteza, que são asseguradas por mecanismos de punição para comportamentos desviantes (North, 1990). Já os laços imersos referem-se a um tipo de relação que ocorre com um conjunto relativamente limitado de parceiros de troca, por um determinado período. A repetição bem sucedida de trocas faz emergir obrigações sociais recíprocas que atenuam a necessidade de regras baseadas em mecanismos formais de governança (Uzzi, 1997).

A imersão relacional é analisada no nível de cada díade, com base no estudo do conteúdo das relações. Ela reflete, assim, o quanto de capital social coletivo, incluindo confiança e solidariedade, está imbricado na relação, de modo a estimular ou restringir o comportamento da firma (Coleman, 1988; Granovetter, 1985; Zaheer, McEvily, \& Perrone, 1998), o que limita o oportunismo e a violação de expectativas coletivas (Rangan, 2000). 0 desenvolvimento da confiança e da solidariedade é visto, assim, como um efetivo mecanismo de controle social, eliminando a necessidade de controles hierárquicos diante do risco de perdas de reputação (Dyer \& Singh, 1998; Gulati, 1995; Kuwabara \& Sheldon, 2012; Lado et al., 2008; Ring \& Van de Ven, 1992).

A literatura sobre o tema preconiza largamente que a confiança possui um efeito positivo na relação comprador-fornecedor (como revisão, ver McEvily, 2011). Apesar de sua con- 
ceitualização ser convergente no nível individual (McEvily \& Tortoriello, 2011), a grande variedade de abordagens dos trabalhos que examinam a natureza da confiança entre firmas inviabiliza a comparação entre os resultados encontrados e acaba por limitar o avanço do conhecimento da confiança intraorganizacional (McEvily, 2011). Questões relevantes para o campo, que não serão discutidas neste trabalho, ainda permanecem em aberto: a confiança configura-se como resultado do comportamento colaborativo, como em Chen, Yen, Rajkumar e Tomochko (2011), ou é antecedente dele, como em Nyaga, Whipple and Lynch (2010)?

A maioria dos autores postula que o controle social gerado pela imersão na rede substitui os mecanismos formais de governança (Gulati, 1998; Gulati, Nohria, \& Zaheer, 2000; Jones, Hesterly, \& Borgatti, 1997). Outros autores, como Poppo e Zenger (2002) e Stikin (1995), partem da premissa de que o controle social tem papel complementar aos mecanismos formais. Uma terceira corrente teórica explora o papel moderador que a imersão apresenta na rede, ao atenuar a relação positiva entre os riscos de transações e a adoção de mecanismos formais de governança (Ring \& Van de Ven, 1992).

Ainda que de modos diferentes, neste artigo, advogase que tanto a imersão estrutural quanto a relacional afetam a ação econômica das firmas nas trocas relacionais, sejam elas horizontais (entre organizações similares) ou verticais (entre clientes e fornecedores). Em especial, neste trabalho, definimos hipóteses baseadas nos mecanismos dos diferentes tipos de imersão para relacionamentos que a firma desenvolve verticalmente a jusante e a montante, com clientes e fornecedores.

\section{HIPÓTESES}

A primeira hipótese do estudo deriva da essência da literatura de redes, que estabelece que a imersão da firma na rede favorece a construção de mecanismos de capital social, como a confiança e a solidariedade (Gulati \& Gargiulo, 1999; Lado et al., 2008). A presença de tais mecanismos na relação estimula ou restringe o comportamento das firmas participantes (Coleman, 1988; Granovetter, 1985; Kuwabara \& Sheldon, 2012; Zaheer et al., 1998), permitindo o desenvolvimento de estruturas de governança interfirmas que favoreçam melhor desempenho (Dyer \& Singh, 1998; Poppo \& Zenger, 2002).

A melhoria do desempenho é atingida pelo fato de a confiança e a solidariedade proporcionarem maior fluidez à relação devido: ao melhor alinhamento dos interesses coletivos e objetivos comuns (Coleman, 1988; Granovetter, 1985), pelo compartilhamento de informações, pela disposição dos membros em serem flexíveis (Johnston, McCutcheon, Stuart, \& Kerwood,
2004), pela aquisição de capacidades organizacionais (Vasconcelos \& Oliveira, 2012) e pela resolução conjunta de problemas entre as partes (Gulati, 1995; Uzzi, 1996, 1997).

É possível, assim, apontar quatro mecanismos de ganhos, com base na imersão relacional, que proporcionariam desempenho superior aos membros da relação:

- Investimentos em ativos específicos. Ativos específicos são aqueles que não são reempregáveis em outro parceiro, sem perda de valor. 0 investimento neste tipo de ativo deve ocorrer na presença de arranjos de governança eficazes, baseados em confiança e com menor risco de comportamento oportunista. Tem-se, com isso, potencial para criação de diferenciação de produto, melhoria da qualidade e no tempo do ciclo de produção, além de menores custos na cadeia (Dyer, 1997; Dyer \& Singh, 1998). 0 crescimento da parceria permite economia de escalas e de escopo na transação, potencializando os ganhos do relacionamento (Dyer \& Singh, 1998).

- Troca de conhecimento. Ocorre pelo aprendizado em conjunto de informação e know how relevantes, como resultado da adoção de transparência e de trocas constantes (Dyer \& Hatch, 2006; Holcomb \& Hitt, 2007). Tal aprendizado resulta em sinergia entre as partes, de forma que esforços sejam economizados, culminando em menores custos de coordenação entre os membros (Holcomb \& Hitt, 2007; Claro \& Claro, 2004) e no melhor entendimento das necessidades dos parceiros (Cheung, Myers, \& Mentzer, 2010).

- Complementaridade de recursos. A criação de produtos ou serviços é resultante da combinação única de recursos entre os membros. A sinergia resultante de seu uso comum proporciona maior retorno, visto que, em conjunto, são difíceis de imitar ou substituir, e produzem resultado diferenciado e superior (Dyer \& Singh, 1998; Holcomb \& Hitt, 2007; Rungtusanatham, Choi, Hollingworth, Wu, \& Forza, 2003).

- Menores custos de transação como resultantes de mecanismos mais eficazes de governança. Tradicionalmente, para se proteger de comportamentos oportunistas, as empresas buscam adotar salvaguardas que podem ser formais, como medidas financeiras, contratuais e mecanismos de controles, ou informais. A visão relacional sugere que os mecanismos informais, baseados em confiança e reputação, são mais efetivos, na medida em que 
podem reduzir custos de barganha, monitoramento e controle (Dyer \& Singh, 1998). Balestrin e Arbage (2007), em um estudo com duas associações produtivas, reforçam o papel dos custos de transação para aglomerados locais de pequenas e médias empresas, um contexto semelhante ao deste estudo.

Espera-se, assim, que a imersão relacional (i.e, desenvolvimento de laços com maior confiança e solidariedade) atue de maneira positiva no desempenho operacional da firma. Acreditase, contudo, que o desenvolvimento de mecanismos relacionais com clientes e com fornecedores possa trazer benefícios diferentes para a firma. A melhor coordenação das atividades resulta no desenvolvimento de atendimento mais adequado aos clientes, traduzido em um melhor desempenho da firma em termos de qualidade. Para a relação com fornecedores, essa melhor coordenação das atividades é combinada com menores custos de controle, o que leva a firma a alcançar ganhos de produtividade na sua operação. Em face desses argumentos, derivam-se as seguintes hipóteses:

H1a: A solidariedade e a confiança afetam positivamente 0 desempenho operacional da firma.

$\mathrm{H}_{1} \mathrm{~b}$ : $\mathrm{O}$ efeito da solidariedade e da confiança com fornecedores é maior na produtividade, enquanto com clientes é maior na qualidade.

A segunda hipótese do estudo também parte do princípio que o desenvolvimento da confiança e da solidariedade nas relações interorganizacionais leva a firma a ser mais produtiva. Neste trabalho, contudo, pretendemos avaliar seu papel moderador entre a terceirização de atividades e os ganhos de produtividade. A análise do processo de terceirização evoluiu e possui hoje um cunho estratégico. As primeiras análises recaíam sobre aquelas atividades normalmente consideradas de preocupação periférica para a organização, como restauração, limpeza e segurança. A discussão acerca de fazer ou comprar (make-or-buy) tem incluído áreas críticas em toda cadeia de valor, tais como design, fabricação, comercialização, distribuição e sistemas de informação (Mclvor, 2000).

Em termos de base teórica, essa discussão migrou da simples abordagem do custo da transação (Williamson, 1975) para o valor da transação (Zajac \& Olsen, 1993). A decisão de terceirizar pode estar, assim, ligada tanto à eficiência operacional quanto à busca de agregação de valor. A análise das relações interfirmas, sob as óticas da teoria de redes sociais e da visão relacional da estratégia, claramente integra essas duas perspectivas. Dessa forma, assumindo que, ao terceirizar, a firma avaliou que o mercado pode desempenhar determinada atividade melhor que ela própria, espera-se que a terceirização leve-a a ser mais produtiva. Adicionalmente, como os mecanismos relacionais proporcionam melhoria na coordenação das atividades e redução dos custos de controle, espera-se que, quanto maior a confiança e a solidariedade nessa relação, maior seja o efeito da terceirização na produtividade da firma.

H2: Quanto maior a solidariedade e a confiança nos fornecedores, maior a influência dos custos de terceiros na produtividade.

A terceira hipótese do estudo combina as decisões de imersão estrutural e relacional e discute o tipo de paradoxo que estas podem levar à firma. 0 paradoxo exposto neste artigo vai além do paradoxo da imersão, exposto em Uzzi (1997), que enfoca aspectos estruturais. Segundo o autor, as firmas enfrentam um paradoxo, pois têm necessidade simultânea de profundidade e amplitude em sua rede de parceiros (Uzzi, 1997). Em outras palavras, o excesso de imersão pode limitar o desenvolvimento de novos laços, a fim de acessar novos conhecimentos e oportunidades (Burt, 1992). Dessa forma, as empresas precisam incorporar os laços imersos e não imersos em suas decisões de seleção de parceiros (Powell, White, Koput, \& Owen-Smith, 2005). A terceira hipótese aqui desenvolvida busca explorar o paradoxo de que firmas podem deparar-se, ao desenvolverem laços verticais imersos estruturalmente (p. ex., vendas concentradas em poucos clientes), sem o desenvolvimento de imersão relacional, com o desenvolvimento de confiança e solidariedade entre os membros. Nesse caso, a firma estaria sujeita a custos de coordenação e controle da relação, bem como ao uso do poder de barganha por parte do cliente (Crook \& Combs, 2007). Embora ainda seja possível observar ganhos operacionais pela imersão estrutural dos laços com clientes (i.e., concentração das vendas), a partir da especialização das rotinas e adequabilidade da oferta, esses ganhos serão maiores na presença da imersão relacional.

H3: Quanto maior a solidariedade e a confiança nos clientes, maior o efeito da concentração de vendas no desempenho operacional.

A quarta e última hipótese do estudo emergiu a partir da identificação de uma característica comum na indústria moveleira: a existência de representantes comerciais, um ator que atua na rede e serve a mais de uma empresa ao mesmo tempo. Tal comportamento remete à Teoria de Dependência de Recursos, que, por sua vez, trata da dependência de que uma empresa tem de quaisquer entradas de fontes externas, por exemplo, conhecimento, capital e trabalho (Pfeffer \& Salancik, 1978). Com efeito, um ator tem poder na medida em que outros dependem de seus 
recursos. Tais recursos criam dependências quando são importantes, quando o controle sobre eles é relativamente concentrado, ou em ambos os casos (Pfeffer \& Salancik, 1978). A magnitude e a criticidade potencializam a dependência do recurso. A magnitude diz respeito à proporção de entradas ou saídas que ele representa. A criticidade é definida pela capacidade de uma empresa de funcionar sem o recurso (Pfeffer \& Salancik, 1978).

Tal dependência de recursos, por sua vez, pode ter raízes relacionais. A firma é analisada como imersa em uma rede de relacionamento de trocas, realizadas em um ambiente de incerteza, e dependente de outras entidades para sobreviver (Pfeffer \& Salancik, 1978). Olhando pela ótica de redes sociais, a dependência pode ter origem na exploração de buracos estruturais da rede. Logo, neste trabalho, tal dependência está relacionada à imersão estrutural das empresas diante de seus intermediários e como aqueles se aproveitam de tais lacunas ou buracos. 0 elemento fundamental dos buracos estruturais está na extensão em que a estrutura social de uma arena competitiva cria oportunidades para certos agentes, por meio de seus relacionamentos. Nesses termos, o controle e a participação na difusão da informação definem o capital social dos buracos estruturais (Burt, 1992). Alguns agentes tornam-se, assim, importantes, por explorarem buracos estruturais da rede para intermediar relações, tornando dependentes as firmas intermediadas. Quanto maior a dependência, maior o poder desse agente (Pfeffer \& Salancik, 1978). No caso do presente estudo, esse agente materializa-se na figura do intermediário de vendas. Ele impede que a firma tenha relacionamento direto com clientes, minando todo o potencial que a imersão nessa relação poderia trazer para a firma (Gulati \& Sytch, 2007). Acredita-se, assim, que firmas que possuem laços diretos com clientes possuam melhor desempenho, o que aponta para a capacidade de captura de valor de agentes que exploram buracos estruturais.

H4: Quanto menor a dependência de intermediários no processo de venda, maior o desempenho operacional.

\section{Figura 1. Modelo de pesquisa}

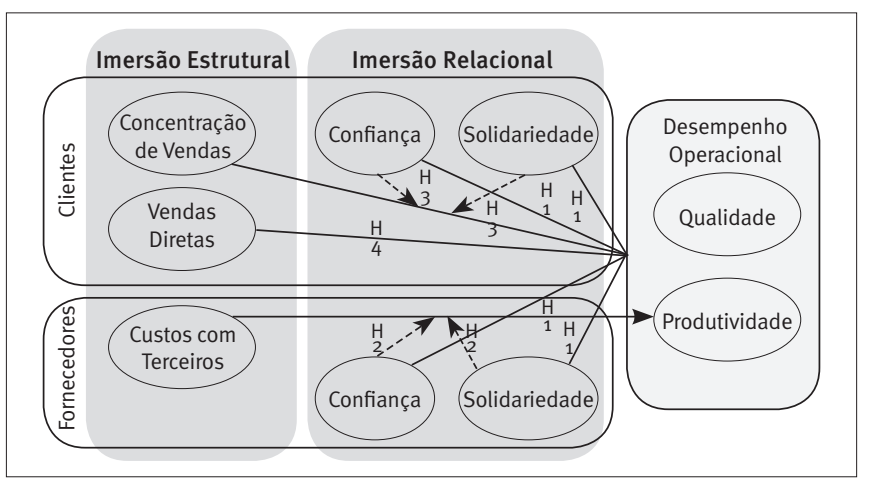

Tendo em vista as hipóteses, na Figura 1, apresentamos o modelo de pesquisa. À direita, está exposta a variável dependente, desempenho operacional, e suas duas dimensões: produtividade e qualidade. No centro, apresentamos as duas dimensões referentes à imersão relacional, confiança e solidariedade, que, além de variáveis independentes, são também moderadoras. Vale ressaltar que, como avaliamos a imersão para o relacionamento com clientes e fornecedores separadamente, as dimensões possuem indicadores distintos para cada tipo de relacionamento, por isso aparecem repetidas no modelo. Já à esquerda, apresentamos as dimensões da imersão estrutural: custos com terceiros (\%) indicando tal tipo de imersão com fornecedores; concentração de vendas (\%) e vendas diretas (\%), que são indicadores da imersão com clientes. Por fim, as hipóteses diretas são demonstradas pelas linhas sólidas, enquanto as hipóteses de moderação são ilustradas pelas linhas pontilhadas. As Hipóteses $1 \mathrm{a}$ e $1 \mathrm{~b}$ foram condensadas em uma única hipótese no diagrama ( $\left.\mathrm{H}_{1}\right)$, já que a segunda é uma hipótese de comparação.

\section{PROCEDIMENTOS METODOLÓGICOS}

\section{Dados e amostra}

Nosso estudo compreendeu a coleta de dados em firmas que necessariamente fabricam móveis de madeira, em quatro dos principais arranjos produtivos da indústria moveleira nacional: Arapongas (PR), composto por 390 empresas, em que conseguimos um total de 20 respondentes; Bento Gonçalves, que sedia 260 empresas em seu polo, no qual foi possível obter 12 casos; Mirassol (SP), em que coletamos 23 questionários dentre as 304 empresas do arranjo; Ubá (MG), que possui 350 empresas, das quais coletamos dados em 20 delas. Ressaltamos que estas empresas que constituem os arranjos não necessariamente produzem predominantemente móveis de madeira, cujo percentual dessas é desconhecido inclusive para as entidades locais.

No total, nossa amostra foi formada com base na adesão de 75 firmas cuja identificação contou com o apoio dos sindicatos patronais e associações locais, que nos forneceram uma listagem. Entendemos que a seleção de casos em diferentes arranjos produtivos locais, com características distintas, aumenta a validade externa do estudo, mesmo sem nos permitir uma generalização para toda a indústria moveleira nacional.

Ademais, a seleção de casos por adesão não nos apontou qualquer tipo de viés de seleção ocasionado por alguma característica que fosse fundamental para compreender o fenômeno aqui estudado. Após tais cuidados, coletamos os dados 
in loco por meio de entrevistas apoiadas por um questionário, no qual tomamos o cuidado de diminuir os riscos de viés de método único (vide Podsakoff \& Organ, 1986) por meio da concepção de medidas de diferentes níveis de mensuração. Além do mais, a coleta das informações por meio de questionário mediada por pesquisadores experientes tende a aumentar a confiabilidade das respostas.

\section{Variável dependente}

Desempenho operacional. Indicadores objetivos de desempenho operacional são difíceis de coletar. Por essa razão, levantamos o entendimento que os gestores tinham do desempenho de sua empresa com base na comparação com as demais, por meio da escala desenvolvida por Gonzáles-Benito (2005). Segundo o autor, os indicadores foram concebidos tendo como referência os cinco objetivos de produção elaborados por Slack, Chambers, Harland, Harrison, e Johnson (1998) - custo, qualidade, flexibilidade, confiabilidade e velocidade, no qual avaliou cada um dos objetivos por meio de escala de cinco itens, em que valores baixos indicam desempenho inferior, e valores altos, desempenho superior.

Em termos operacionais, coletamos os indicadores com base na adaptação e tradução da escala de Gonzáles-Benito (2005), em que, assim como nesse autor, avaliamos a dimensionalidade do construto a partir da análise fatorial exploratória. Extraindo os fatores por meio da análise dos componentes principais e fazendo a rotação por meio do ajuste Varimax, identificamos três fatores por meio do método ScreePlot - produtividade, flexibilidade e qualidade. Juntamente, esses fatores explicaram $70,73 \%$ da variância, cuja avaliação de ajuste do KMO foi de 0,624, e o teste de esfericidade de Bartlett foi significativo ( $p<0,001$ ). Dos três fatores identificados, focamos as dimensões Produtividade, que consistiu de dois itens, Produtividade dos funcionários e Velocidade de produção, cujo alpha de Cronbach foi de 0,719 e a Correlação Intraclasse (ICC) foi de 0,561; e Qualidade, formada pelos itens "Capacidade de atender as necessidades dos clientes no prazo combinado" e "Qualidade do produto", em que o alpha de Cronbach foi de o,613 e a ICC foi de 0,442 .

\section{Variáveis independentes}

Confiança. Para avaliar o grau de confiança que as empresas moveleiras depositam tanto nos fornecedores quanto nos clientes, utilizamos os indicadores presentes no estudo de Lado et al., (2008). Originalmente composta por seis itens, a construção dessa escala reflete a benevolência e a credibilidade associada à confiança (Crosby, Evans, \& Cowles, 1990; Rempel, Holmes, \& Zanna, 1985). Como os autores apontam, existem argumentos que indicam que a confiança é um construto multidimensional (p. ex., Das \& Teng, 2001; Mayer, Davis, \& Schoorman, 1995). Normalmente, todavia, eles se apresentam altamente correlacionados. Por essas razões, escolhemos esse escore unidimensional em que, após nova avaliação da confiabilidade, removemos um indicador, restando, então, os seguintes itens, todos eles avaliados em Likert de 6 pontos (discordo a concordo plenamente): "acreditamos que nossos principais clientes [fornecedores] são honestos nas suas relações conosco"; "nossos clientes [fornecedores] são reconhecidos porque honram os acordos"; "nossos clientes [fornecedores] são sinceros nas suas relações conosco"; "nossos clientes [fornecedores] sempre fazem o que é idôneo"; "temos grande confiança em nossos clientes [fornecedores]". No fim, nosso indicador de Confiança nos fornecedores apresentou um alpha de Cronbach de 0,838 e uma ICC de 0,509. Já o indicador de Confiança nos clientes obteve um alpha de 0,851 e uma ICC de 0,533.

Solidariedade. Nossa segunda dimensão da imersão relacional foi composta com base no uso dos quatro itens desenvolvidos por Lado et al., (2008) para avaliação da dimensão solidariedade, que, originalmente naquele estudo, fazia parte da variável relacionalismo. Desconsideramos as demais dimensões porque estávamos preocupados com o senso positivo das empresas diante de seus clientes e fornecedores, e não com a intensidade da relação em si. Com os dados coletados, avaliamos tais indicadores a partir de escala Likert de 6 pontos, em que, após avaliação da confiabilidade, restaram dois indicadores: "estamos comprometidos com a preservação de um bom relacionamento com os principais clientes [fornecedores]" e "nós conscientemente tentamos manter um relacionamento cooperativo com os principais clientes [fornecedores]". Dessa forma, obtivemos um alpha de Cronbach de 0,765 e uma ICC de 0,620 para Solidariedade com os fornecedores e um alpha de Cronbach de o,879 e uma ICC de 0,783 para Solidariedade com os clientes.

Custos com terceiros (\%). Para avaliar o quanto as organizações industriais moveleiras estão envolvidas com os seus fornecedores, avaliamos o impacto dos custos com terceirização e com compras no custo total de produção em termos percentuais. Quanto maior o custo com terceiros, maior a dependência de fornecedores e terceirizados. Coletamos esse indicador questionando diretamente os dirigentes das empresas, confrontando-o posteriormente com outros indicadores relacionados ao custo total de compras e de terceirização, com o objetivo de verificar se as respostas eram confiáveis. Tal indicador é con- 
sistente com pesquisas anteriormente realizadas sobre a relação entre magnitude dos custos de terceiros no grau de dependência da organização com suas relações (Gulati \& Sytch, 2007; Pfeffer \& Salancik, 1978).

Concentração de vendas (\%). Diferentemente de estudos sobre imersão que avaliaram a concentração das relações por meio do índice de Herfindahl (Shipilov, 2005; Uzzi, 1996, 1999), nós avaliamos o grau de concentração das vendas, averiguando com os dirigentes das indústrias moveleiras o número de clientes que correspondiam a $80 \%$ do volume de compras, tal como o total de clientes. De posse desses indicadores, nós criamos um índice de concentração a partir da seguinte fórmula: (N. clientes - N. clientes que totalizam $80 \%$ das vendas $\div$ N. clientes) x 100. Quanto maior o valor desse indicador, maior o grau de imersão das vendas das empresas nas relações em poucos laços, e quanto menor, mais engajada a organização está em trocas abertas com o mercado (arm's lenght ties, vide Uzzi, 1996). Vale destacar que os dois indicadores de imersão estrutural empregados são análogos à noção de densidade da rede, sendo, inclusive, medidas aproximadas daquelas usadas em alguns estudos (p. ex., Echols \& Tsai, 2005; Gilsing, Nooteboom, Vanhaverbeke, Duysters, \& Oord, 2008; Rowley et al., 2000).

Venda direta (\%). Avaliamos o quanto as indústrias moveleiras são independentes de intermediários no processo de venda a partir da avaliação do percentual das vendas diretas em relação ao total. Como apontado na literatura, quanto maior a dependência de intermediários no processo, menor a capacidade de as organizações gerarem valor (Burt, 1992, 2005) e menor o controle sobre as margens e preço final (Pfeffer \& Salancik, 1978).

\section{Variável de controle}

Tamanho da empresa. Controlamos o efeito das variáveis independentes e moderadoras com base no tamanho da empresa em relação ao número de funcionários. Desconsideramos o faturamento como controle, por apresentar alta correlação com o número de funcionários $(r=0,744, \mathrm{p}<0,001)$ e também apresentar mais casos perdidos. Como há poucos casos, removemos algumas variáveis de controle que poderiam influenciar o modelo (idade da empresa, tipo de negociação e polo em que a empresa está localizada). Tal remoção, no entanto, não influenciou os resultados, pois verificamos que, de todas as variáveis de controle, somente o número de funcionários mostrou-se significativamente relacionado com as variáveis dependentes (qualidade e produtividade) no modelo Manova (Pillais's Tra$c e=0,141, \mathrm{p}=0,018)$.

\section{Método}

Para testar nossas hipóteses, utilizamos modelos de regressão linear hierarquizados por meio do método dos mínimos quadrados ordinários (OLS Model). Para avaliar o ajuste e robustez de tal modelo, tal como se ele era o mais adequado, em primeiro lugar, verificamos que a variável dependente apresentavase aproximadamente normal, com simetria e curtose menor que 1,5. Em segundo lugar, avaliamos qual a melhor forma funcional da relação entre variáveis independentes e dependentes, que apontou para melhor ajuste da função linear. Em terceiro lugar, avaliamos se os erros apresentavam problemas de heterocedasticidade, o que não foi identificado por meio do teste de White. Também avaliamos se os modelos apresentavam problemas de multicolinearidade por meio da avaliação da tolerância, que não se mostraram inferiores a 0,2, e a partir do fator de inflação da variância (VIF), que não apresentaram valores maiores que 5. Por fim, avaliamos se havia observações influentes, em que não identificamos casos atípicos (resíduos padronizados elevados), nem como alavancadores, já que a distância de Cook, de Mahalanobis, a alavancagem e o desvio dos coeficientes estavam dentro dos padrões aceitos.

Para a análise da moderação, multiplicamos as variáveis custos com terceiros e concentração pelas variáveis confiança e a solidariedade, em que salvamos seus produtos como novas variáveis. Para evitar problemas de colinearidade, o que enviesaria os coeficientes das variáveis, adotamos o procedimento proposto por Cronbach (1987) e apresentado por Jaccard, Torrisi e Wan (1990), de centrar as variáveis antes de efetuar o seu produto, ou seja, dividimos o valor de cada caso pela média da respectiva variável.

\section{RESULTADOS}

Para poder verificar todas as hipóteses, apresentamos os resultados em quatro tabelas. Nas duas primeiras, focamos os laços com os fornecedores, em que são apresentados os efeitos da imersão relacional (confiança e solidariedade) e estrutural (custos com terceiros) na produtividade, na Tabela 1. Já esses mesmos efeitos na qualidade podem ser vistos na Tabela 2. Nas demais tabelas, atentamos para os laços com os clientes, em que a influência da imersão relacional e da estrutural (concentração de vendas) na produtividade pode ser vista na Tabela 3, e na qualidade, na Tabela 4. 


\section{TABELA 1. Efeito da imersão com fornecedores na produtividade}

\begin{tabular}{|c|c|c|c|c|c|c|c|}
\hline & Model 1 & Model 2 & Model 3 & Model 4 & Model 5 & Model 6 & Model 7 \\
\hline Custos com terceiros (\%) $\mathrm{x}$ & & & & & & & $0,012^{\star}$ \\
\hline Solidariedade com fornecedores & & & & & & & $(0,007)$ \\
\hline Confiança nos fornecedores & & & & $(0,005)$ & & & \\
\hline Custos com terceiros (\%) & & & $0,008^{* *}$ & $0,008^{\star *}$ & & $0,009^{\star *}$ & $0,009^{\star \star}$ \\
\hline \multirow[t]{2}{*}{ Solidariedade com fornecedores } & & & & & $-0,247^{\star}$ & $-0,299^{\star \star}$ & $-0,290, * *$ \\
\hline & & & & & $(0,144)$ & $(0,138)$ & $(0,136)$ \\
\hline \multirow[t]{2}{*}{ Confiança nos fornecedores } & & $-0,076$ & $-0,139$ & $-0,217^{*}$ & & & \\
\hline & & $(0,116)$ & $(0,115)$ & $(0,115)$ & & & \\
\hline Constante & $(0,128)$ & $(0,116)$ & $(0,562)$ & $(0,567)$ & $(0,800)$ & $(0,763)$ & $(0,750)$ \\
\hline $\mathrm{F}$ & $2,847^{\star}$ & 1,638 & $2,663^{\star *}$ & $3,605^{\star \star *}$ & $2,925^{*}$ & $3,835^{\star *}$ & $3,875^{\star * \star}$ \\
\hline $\mathrm{R}^{2}$ ajustado & 0,025 & 0,017 & 0,066 & 0,128 & 0,050 & 0,107 & 0,139 \\
\hline $\mathrm{R}^{2}$ & 0,038 & 0,044 & 0,105 & 0,177 & 0,076 & 0,145 & 0,188 \\
\hline$\Delta R^{2}$ & - & 0,006 & 0,061 & 0,072 & 0,038 & 0,069 & 0,043 \\
\hline
\end{tabular}

Erro padrão entre parênteses. $n=75 .{ }^{* \star *} p<0,01{ }^{\star *} p<0,05{ }^{*} p<0,1$

\section{TABELA 2. Efeito da imersão com fornecedores na qualidade}

\begin{tabular}{|c|c|c|c|c|c|c|c|}
\hline & Model 1 & Model 2 & Model 3 & Model 4 & Model 5 & Model 6 & Model 7 \\
\hline Solidariedade com fornecedores & & & & & & & $(0,006)$ \\
\hline Custos com terceiros (\%) $\mathrm{x}$ & & & & 0,003 & & & \\
\hline Confiança nos Fornecedores & & & & $(0,004)$ & & & \\
\hline \multirow[t]{2}{*}{ Solidariedade com fornecedores } & & & & & 0,089 & 0,124 & 0,124 \\
\hline & & & & & $(0,114)$ & $(0,115)$ & $(0,116)$ \\
\hline \multirow[t]{2}{*}{ Confiança nos fornecedores } & & 0,104 & 0,103 & 0,083 & & & \\
\hline & & $(0,090)$ & $(0,093)$ & $(0,097)$ & & & \\
\hline \multirow[t]{2}{*}{ Constante } & $4,112^{\star \star \star}$ & $3,631^{\star \star \star}$ & $3,725^{\star \star *}$ & $3,827^{\star \star \star}$ & $3,623^{\star \star \star}$ & $3,541^{\star \star \star}$ & $3,539^{\star \star \star}$ \\
\hline & $(0,099)$ & $(0,427)$ & $(0,457)$ & $(0,478)$ & $(0,630)$ & $(0,634)$ & $(0,639)$ \\
\hline $\mathrm{F}$ & $6,951^{\star \star \star}$ & $4,163^{\star *}$ & $3,033^{\star \star}$ & $2,401^{\star \star}$ & $3,766^{\star \star}$ & $3,008^{\star \star}$ & $2,225^{*}$ \\
\hline$R^{2}$ ajustado & 0,075 & 0,080 & 0,079 & 0,073 & 0,070 & 0,078 & 0,065 \\
\hline $\mathrm{R}^{2}$ & 0,088 & 0,105 & 0,118 & 0,125 & 0,096 & 0,117 & 0,117 \\
\hline$\Delta R^{2}$ & - & 0,017 & 0,013 & 0,007 & 0,008 & 0,021 & 0,000 \\
\hline
\end{tabular}

Erro padrão entre parênteses. $n=75 .{ }^{* \star *} p<0,01{ }^{* \star} p<0,05 * p<0,1$ 
TABELA 3. Efeito da imersão com clientes na produtividade

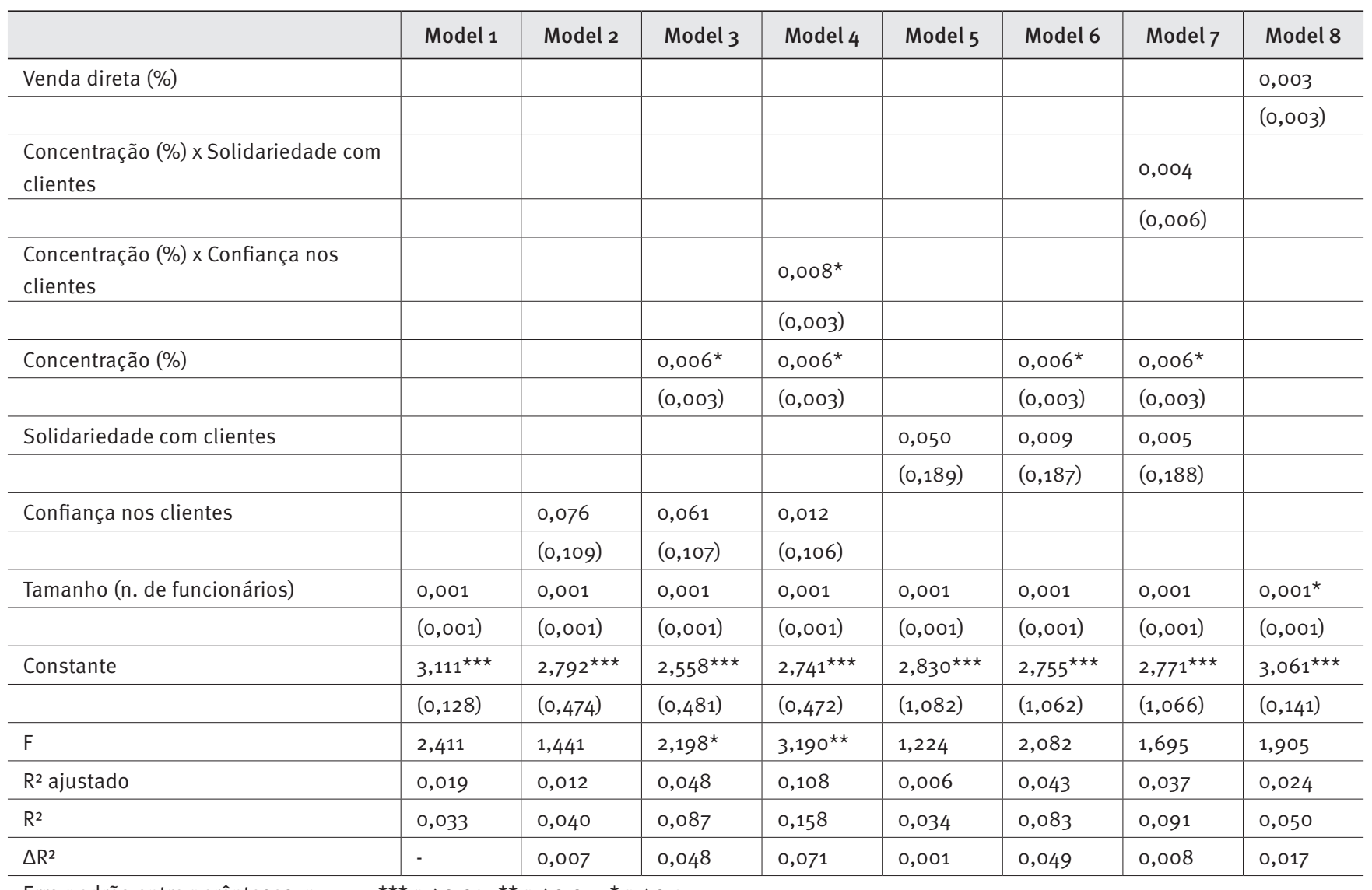

Erro padrão entre parênteses. $n=75 .{ }^{\star \star \star} p<0,01{ }^{* \star} p<0,05{ }^{*} p<0,1$

TABELA 4. Efeito da imersão com clientes na qualidade

\begin{tabular}{|c|c|c|c|c|c|c|c|c|}
\hline & Model 1 & Model 2 & Model 3 & Model 4 & Model 5 & Model 6 & Model 7 & Model 8 \\
\hline Venda direta (\%) & & & & & & & & $(0,002)$ \\
\hline $\begin{array}{l}\text { Concentração (\%) x Solidariedade com } \\
\text { clientes }\end{array}$ & & & & & & & $(0,004)$ & \\
\hline Concentração (\%) x Confiança nos clientes & & & & $-0,006^{\star \star}$ & & & & \\
\hline \multirow[t]{2}{*}{ Concentração (\%) } & & & 0,002 & 0,002 & & 0,002 & 0,002 & \\
\hline & & & $(0,002)$ & $(0,002)$ & & $(0,002)$ & $(0,002)$ & \\
\hline \multirow[t]{2}{*}{ Solidariedade com clientes } & & & & & $0,355^{\star \star}$ & $0,343^{\star \star}$ & $0,340^{\star \star}$ & \\
\hline & & & & & $(0,138)$ & $(0,139)$ & $(0,130)$ & \\
\hline Confiança nos clientes & & $0,154^{\star}$ & $0,149^{*}$ & $0,186^{\star \star}$ & & & & \\
\hline Constante & $(0,098)$ & $(0,353)$ & $(0,366)$ & $(0,359)$ & $(0,788)$ & $(0,791)$ & $(0,793)$ & $(0,107)$ \\
\hline $\mathrm{F}$ & $8,512^{\star \star \star}$ & $6,230^{\star * *}$ & $4,405^{\star \star \star}$ & $4,926^{\star \star \star}$ & $7,904^{\star \star \star}$ & $5,435^{\star \star \star}$ & $4,211^{\star \star \star}$ & $5,911^{\star \star \star}$ \\
\hline $\mathrm{R}^{2}$ ajustado & 0,094 & 0,127 & 0,124 & 0,179 & 0,161 & 0,156 & 0,151 & 0,117 \\
\hline $\mathrm{R}^{2}$ & 0,107 & 0,151 & 0,161 & 0,225 & 0,184 & 0,191 & 0,199 & 0,141 \\
\hline$\Delta R^{2}$ & - & 0,044 & 0,010 & 0,064 & 0,077 & 0,007 & 0,007 & 0,034 \\
\hline
\end{tabular}

Erro padrão entre parênteses. $n=75 .{ }^{* *} p<0,01{ }^{* *} p<0,05{ }^{*} p<0,1$ 
Em todas as tabelas, no Modelo 1, apresentamos o coeficiente e o erro padrão da variável de controle (número de funcionários) na produtividade ou qualidade. Já nos Modelos 2 e 4, acrescentamos as variáveis referentes à imersão relacional: confiança e solidariedade. Como podemos observar na Tabela 1, o mecanismo relacional de confiança nos fornecedores não apresentou influência significativa sobre a produtividade (vide Modelo 2), enquanto a solidariedade apresentou efeito negativo (Modelo 5). Quando avaliamos os efeitos da imersão relacional na qualidade (Modelos 2 e 5 da Tabela 2), também não verificamos influência desses dois mecanismos. Em suma, no que se refere aos laços com os fornecedores, encontramos um efeito direto nulo, e até contrário ao normalmente declarado nas teorias acerca da confiança e do capital social. Como pode ser observado claramente no Modelo 5 da Tabela 1, ser solidário com os fornecedores está associado a menor produtividade.

No caso da imersão relacional por meio da confiança e da solidariedade depositada nos clientes, não há evidências de efeito significativo na produtividade (Modelos 2 e 5 da Tabela 3), enquanto na qualidade essa influência é positiva tanto para a confiança (beta $=0,154$ ) quanto para a solidariedade, cujo beta foi de 0,355 (Modelos 2 e 5 da Tabela 4). Os resultados dão a entender, assim, que, mesmo não havendo efeito significativo e positivo de estar relacionalmente imerso com os clientes na produtividade, há ganhos aparentes em termos de qualidade.

Tendo em vista tais resultados, não podemos corroborar a Hipótese 1a, já que foi encontrada influência positiva somente para a imersão relacional com os clientes. Podemos confirmar, no entanto, pelo menos parcialmente, a Hipótese 1 b, pois verificamos que a influência de estar imerso relacionalmente com os clientes tem efeito na qualidade, e não na produtividade. Já no caso da imersão relacional com os fornecedores, não há relação com melhora da qualidade, porém, mesmo que negativamente, há influência da solidariedade na produtividade. Em suma, os dados nos levam a suportar que a qualidade é sensível aos laços com clientes e a produtividade, aos laços com fornecedores.

Mesmo não havendo hipóteses sobre os efeitos da imersão estrutural no desempenho operacional, até porque há fortes evidências de seus efeitos registrados na literatura (Rowley et al., 2000; Shipilov, 2005; Uzzi, 1996), testamos esses efeitos individualmente. Como destacado no Modelo 3 da Tabela 1, há ganhos significativos de produtividade (beta $=0,008)$ quando há maior grau de terceirização, indicado pela proxy custos de terceiros (\%), indo ao encontro da literatura. Tal efeito na qualidade mostrou-se nulo (Modelo 3 da Tabela 2), o que leva a entender que maior custo com terceiros não levou a um incremento significativo da qualidade. No caso do aumento da imersão estrutural por meio da concentração de vendas em poucos clientes, obser- vamos um efeito positivo na produtividade (beta $=0,006$, Modelo 3 da Tabela 3), mas nulo na qualidade. Dessa forma, no caso estudado, verificamos que concentrar as vendas gera ganhos de eficiência produtiva, mas não há evidências de que isso possa ser revertido, pelo menos diretamente, em melhor qualidade.

Entretanto, como propusemos, estamos mais interessados na combinação dos efeitos da imersão estrutural e relacional do que nos seus efeitos individuais. Sendo assim, buscamos avaliar como a imersão relacional, em termos de confiança e solidariedade, modera o efeito dos custos com terceiros na produtividade e da concentração de vendas, tanto na produtividade quanto na qualidade.

Retornando à Tabela 1, podemos verificar que a interação entre custos com terceiros e confiança é significativa (beta = 0,011, Modelo 4), tal como a interação entre esse primeiro indicador e a solidariedade (beta $=0,012$, Modelo 7), levando a corroborar a Hipótese 2. Como ilustrado na Figura 2, quanto maiores a confiança e a solidariedade depositadas nos fornecedores, maiores os benefícios do aumento nos custos de terceiros para a produtividade. Merece destaque, também, o fato de a imersão relacional apresentar efeito direto negativo, em que maior confiança e solidariedade levam a menor produtividade, porém, paradoxalmente, quando há aumento na imersão estrutural por meio do aumento dos custos com terceiros, essa influência torna-se positiva.

Quando observamos os efeitos da interação entre os mecanismos relacionais e os estruturais, tendo em face os laços com clientes, encontramos influência significativa na relação entre confiança e concentração de vendas na produtividade (beta $=0,008$, Modelo 4 da Tabela 3). No entanto, não encontramos efeito moderador significativo da solidariedade na produtividade (Modelo 7 da Tabela 3) nem na qualidade (Modelo 7 da Tabela 3). Focando somente a qualidade (Tabela 4), nos deparamos com outro paradoxo: enquanto há moderação positiva e significativa da confiança na relação entre concentração de vendas e produtividade, a influência na qualidade é negativa (beta $=-0,006$, Modelo 4). Tais relações estão ilustradas na Figura 3. Enquanto maior confiança nos clientes leva a maior produtividade, com o aumento da concentração de vendas, no caso da qualidade, quanto maior a confiança, piores os efeitos da concentração. Diante desses resultados, apesar de instigantes, não podemos corroborar a Hipótese 3.

Por fim, avaliando o efeito das vendas diretas, que é um indicador de dependência de intermediários, encontramos relação significativa e positiva somente na qualidade (Modelo $8 \mathrm{da}$ Tabela 4), enquanto que para a produtividade a influência não foi significativa (Modelo 8 da Tabela 3), o que nos permite suportar a Hipótese 4 apenas parcialmente. 
Figura 2. Moderação da imersão relacional na relação entre custos com terceiros e produtividade
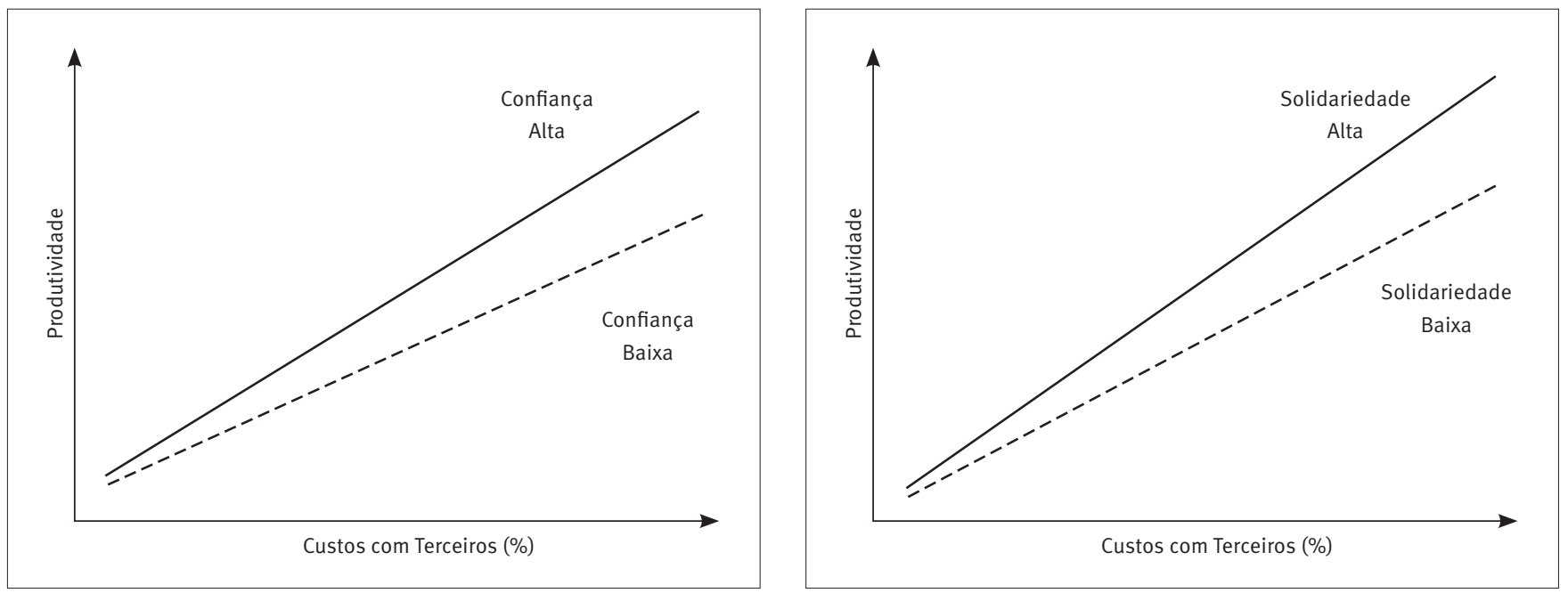

Figura 3. Moderação da confiança na relação entre concentração de vendas e desempenho operacional
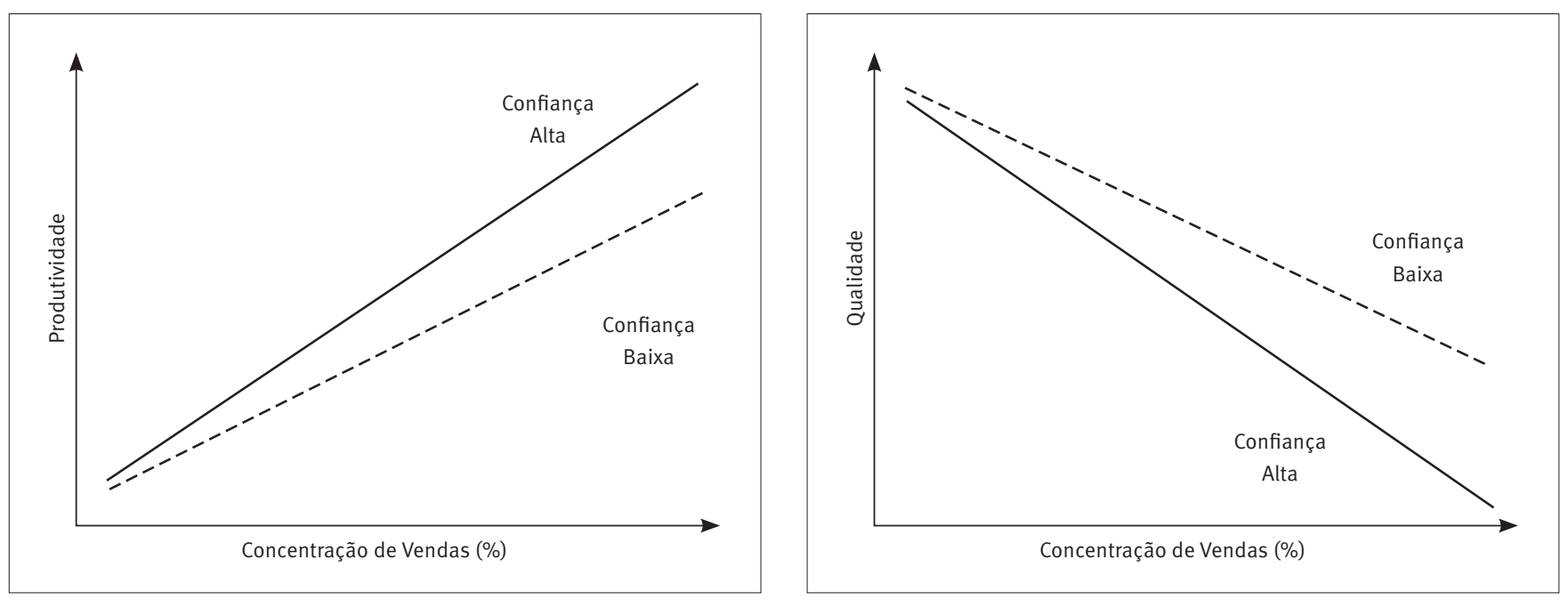

\section{DISCUSSÃO E CONCLUSÃO}

Partindo de uma perspectiva relacional da estratégia, o objetivo deste artigo foi analisar os efeitos da imersão relacional e estrutural no desempenho operacional em termos de ganhos de produtividade e qualidade. Para tanto, operacionalizamos a imersão estrutural com base na investigação dos custos percentuais com fornecedores e com a concentração de vendas em poucos clientes, enquanto investigamos a imersão relacional a partir do grau de confiança e solidariedade que depositam nesses relacionamentos. Mais que isso, investigamos como esses diferentes tipos de imersão reinforçam um ao outro.

Ao analisar os efeitos dos mecanismos de imersão relacional no desempenho operacional, não conseguimos achar suporte para nossa primeira hipótese, no entanto os resultados

mostraram-se muito mais interessantes do que imaginávamos. 0 que podemos observar foi que apresentar laços de confiança teve influência positiva e significativa somente para a relação com os clientes, e especificamente na qualidade do produto. Esse resultado vai ao encontro do que Dyer e Hatch (2006) e Holcomb e Hitt (2007) apontaram como benefícios da imersão para a troca de conhecimento e para a resolução de problemas em conjunto.

Mais instigante ainda foi a relação negativa entre solidariedade com os fornecedores e produtividade. Como dimensão relacional, a solidariedade aponta para o senso positivo que um ator tem em relação aos seus pares (Lado et al., 2008). No nosso estudo, esse senso positivo aparentemente abre brechas para que os fornecedores sejam oportunistas nas negociações, o que acaba corroendo as margens de produtividade das 
firmas, ou seja, por mais evidências de benefícios existentes da qualidade das relações entre parceiros, ela também pode possibilitar caminhos para que um dos laços da relação, em especial os fornecedores, se aproveite da solidariedade das firmas moveleiras em negociações de preços dos insumos e de prestação de serviços. Apesar de contrário ao que propusemos, há indícios na literatura de que parceiros podem se aproveitar de sua boa avaliação e da confiança depositada para auferir maiores margens, o que implicou, neste estudo, um efeito negativo direto da imersão relacional com fornecedores. Tal comportamento foi discutido por Granovetter (1985) e está presente nos resultados de Uzzi e Lancaster (2004), Villena, Revilla e Choi (2011) e Rogan (2013). Isso remete à necessidade de se considerarem mecanismos complementares de governança que vão além da imersão relacional, como contratos formais, com o objetivo de evitar a expropriação dos resultados da firma pelos seus parceiros (Hoetker \& Mellewigt, 2009; Poppo \& Zenger, 2002).

Tendo esses dois resultados em conjunto, conseguimos verificar que a relação entre imersão relacional e as diferentes facetas do desempenho apresenta um efeito condicionado tanto pelo tipo de agente que se relaciona quanto pela natureza do resultado, o que vai ao encontro do que propusemos na Hipótese $1 b$, adicionando ainda mais complexidade aos estudos sobre relações interorganizacionais. Em síntese, nossas evidências indicam que, pelo menos para a indústria moveleira nacional, a qualidade é sensível aos laços com clientes e a produtividade, aos laços com fornecedores.

Assim como destacado na literatura sobre os efeitos da imersão estrutural (Rowley et al., 2000; Shipilov, 2005; Uzzi, 1996), nossos resultados apontaram para um efeito significativo do aumento dos custos com terceiros, representando o grau de terceirização e a dependência dos fornecedores, como condicionante da produtividade das indústrias moveleiras. Verificamos também esse efeito quando analisamos os laços com clientes, em que concentrar as vendas gerou ganhos de eficiência produtiva. Razões para que isso ocorra são fortes na literatura, pois há evidências de que o aumento da imersão estrutural facilita a troca de conhecimento (Cheung et al., 2010), reduz os custos de transação e permite ganho de escala e escopo (Dyer \& Singh, 1998), bem como aumenta a complementaridade de recursos (Dyer, 1997; Holcomb \& Hitt, 2007; Rungtusanatham et al., 2003).

Buscando verificar o quanto a imersão relacional e estrutural reinforçam uma à outra, identificamos que quanto maior o grau de confiança e solidariedade depositada nos fornecedores, maiores são os ganhos de produtividade gerados pelo aumento dos custos com terceiros. Como já havíamos demonstrado, entretanto, quando olhamos somente para a influência direta dos mecanismos de governança relacionais, eles suge- rem um efeito negativo sobre a produtividade. Apesar de corroborar nossa segunda hipótese, os dados nos sugerem que há um efeito paradoxal da imersão social na produtividade: nos casos em que há confiança e solidariedade entre firmas e fornecedores, mas com baixo grau de terceirização, os efeitos sobre a produtividade são negativos ou nulos; já quando há maior grau de terceirização, os resultados são positivos.

Essa contradição reforça a ideia de que a imersão social e a estrutural são mecanismos complementares de governança, em que uma depende da outra para se obterem vantagens. Olhando para o fenômeno estudado, apresentar maior grau de terceirização requer da firma conhecimento sobre como lidar eficientemente com fornecedores, enquanto confiar e ser solidário com eles diminui a necessidade de contratos formais, reduz os custos de transação e facilita a aprendizagem conjunta (Cheung et al., 2010; Dyer \& Singh, 1998; Poppo \& Zenger, 2002). Esses mecanismos só foram efetivos, todavia, quando utilizados em conjunto.

Analisando esse mesmo imbricamento, mas tendo como referência a imersão relacional e estrutural com clientes, identificamos outro efeito paradoxal, mas de natureza diferente: nossos resultados demonstraram que quanto maior a confiança nos clientes, maior a influência da concentração de vendas na produtividade, o que dá a ideia de mecanismos que envolvem a complementaridade de recursos e menores custos de transação beneficiando ambos os lados. Mas o paradoxo ocorre no efeito da imersão na qualidade: em vez de estimular outro mecanismo relacional, que envolve a solução conjunta de problemas com o objetivo de melhorar a qualidade dos produtos, aparentemente os resultados apontam para uma queda na qualidade. Mas quais seriam as razões para que esse efeito ocorra? Uma das hipóteses é que seja um comportamento oportunista do vendedor, nesse caso, a indústria de móveis, que deixa de priorizar a qualidade por gozar da confiança e da boa vontade do cliente. Outra hipótese seria uma característica estrutural da atividade, em que empresas que focam o custo, em vez da qualidade, tenham preferências por trocas mais imersas e coesas.

Por fim, olhando para o grau de dependência das firmas moveleiras em relação aos intermediários no processo de venda, não verificamos relação alguma com a produtividade. Se há algum tipo de perda econômica da indústria em relação à dependência de terceiros no processo de vendas, aparentemente ela não se dá em termos de produtividade, mas talvez como queda na margem de contribuição. Já em relação à qualidade, verificamos relação positiva com o grau de independência das firmas moveleiras. Os resultados apontam que quanto maior o percentual de venda direta, melhor a qualidade do produto. Isso sugere que estar mais próximo dos clientes facilita a resolução de problemas (Gulati, 1995; 
Uzzi, 1996, 1997), tal como permite às firmas entender melhor as necessidades do cliente final (Cheung et al., 2010).

Esses resultados apresentam importantes implicações para o estudo de redes verticais, tal como para a área de estratégia, já que ressaltam os efeitos da imersão relacional e estrutural no desempenho operacional. A primeira implicação envolve a necessidade de se reconhecer que nem sempre a imersão relacional leva a benefícios, mas também, na ausência de outros mecanismos de governança, pode levar a prejuízo de uma das partes, já que a outra pode se aproveitar do senso de benevolência e solidariedade de uma firma. Aceito isso, nosso estudo evidencia que os mecanismos de imersão relacional e estrutural estão interligados, em que um reforça o outro, o que possibilita benefícios adicionais para as organizações em maior grau do que se fossem usados isoladamente. Em vez de avaliar os efeitos de cada um dos mecanismos de governança individualmente, estudos sobre imersão devem, assim, prezar pela avaliação da combinação dos mecanismos de governança, pois muitos deles podem apresentar efeitos diferentes quando analisados individualmente, até mesmo paradoxais e contraditórios. A segunda implicação remete à necessidade de se considerarem tanto o tipo do agente que se está relacionando quanto a natureza do resultado avaliado. 0 estudo demonstrou que, em redes verticais, os benefícios em termos de qualidade e produtividade variam para as relações com clientes e fornecedores. Estudos sobre redes verticais devem considerar tanto o tipo de ator como a natureza e processo da atividade de que se busca explicar os efeitos.

Dito isso, sugerimos que estudos desse tipo sejam desenvolvidos envolvendo diferentes tipos de negócio, em especial a indústria de criação. Ademais, seria interessante avaliar as implicações da imersão em redes verticais para diferentes tipos de resultados, como formação de preços de produto, crescimento de mercado e rentabilidade. Também deveria ser focada a investigação em redes horizontais, considerando como fatores condicionantes o capital social e a estrutura relacional da rede, o que exigiria um delineamento multinível. Por fim, em vez de avaliar a contribuição dos laços de uma forma geral para a firma, poderse-ia buscar delineamentos em que fosse possível avaliar o valor de cada relação que a empresa estabelece, requerendo métodos de análise de redes sociais mais robustos, em que a unidade de análise fosse a díade, ou até mesmo equações espaciais, que consideram tanto o nível da firma como o da díade.

\section{REFERÊNCIAS}

Baker, W. (1990). Market networks and corporate behavior. American Journal of Sociology, 96(3), 589-625.
Balestrin, A, \& Arbage, A. (2007). A perspectiva dos custos de transação na formação de redes de cooperação. RAE-eletrônica, 6(1), art. 7.

Burt, R. S. (1992). Structural holes: the social structure of competition. Cambridge: Harvard University Press.

Burt, R. S. (2005). Brokerage and closure: an introduction to social capital. Oxford: Oxford University Press.

Chen, J. V, Yen, D. C, Rajkumar, T. M, \& Tomochko, N. A. (2011). The antecedent factors on trust and commitment in supply chain relationships. Computer Standards \& Interfaces, 33(3), 262-270.

Cheung, M. S, Myers, M. B, \& Mentzer, J. T. (2010). Does relationship learning lead to relationship value? A cross-national supply chain investigation. Journal of Operations Management, 28(6), 472-487.

Claro, D, \& Claro, P. (2004). Gerenciando relacionamentos colaborativos com fornecedores. RAE-Revista de Administração de Empresas, 44(4), 68-79.

Coleman, J. S. (1988). Social capital in the creation of human capital. American Journal of Sociology, 94(1), S95-S120.

Cronbach, L. J. (1987). Statistical tests for moderator variables: flaws in analyses recently proposed. Psychological Bulletin, 102(3), 414-417.

Crook, T, \& Combs, J. (2007). Sources and consequences of bargaining power in supply chains. Journal of Operations Management, 25(2), 546555.

Crosby, L. A, Evans, K. R, \& Cowles, D. (1990). Relationship quality in services selling: an interpersonal influence perspective. Journal of Marketing, 54(3), 68-81.

Das, T. K, \& Teng, B. (2001). Trust, control, and risk in strategic alliances: an integrated framework. Organization Studies, 22(2), 251-283.

Dyer, J. H. (1997). Effective interfirm collaboration: how firms minimize transaction costs and maximize transaction value. Strategic Management Journal, 18(7), 553-556.

Dyer, J. H, \& Hatch, N. W. (2006). Relation-specific capabilities and barriers to knowledge transfers: creating advantage through network relationships. Strategic Management Journal, 27(8), 701-719.

Dyer, J. H, \& Singh, H. (1998). The relational view: cooperative strategy and sources of interorganizational competitive advantage. Academy of Management Review, 23(4), 660-679.

Echols, A, \& Tsai, W. (2005). Niche and performance: the moderating role of network embeddedness. Strategic Management Journal, 26(3), 219-238.

Gilsing, V, Nooteboom, B, Vanhaverbeke, W, Duysters, G, \& Oord, A. V. D. (2008). Network embeddedness and the exploration of novel technologies: technological distance, betweenness centrality and density. Research Policy, 37(10), 1717-1731.

Gonzáles-Benito, J. (2005). A study of the effect of manufacturing proactivity on business performance. International Journal of Operation \& Production Management, 25(3), 222-241.

Granovetter, M. (1985). Economic action and social structure: the problem of embeddedness. American Journal of Sociology, 91(3), 481-510.

Grover, V, \& Malhotra, M. K. (2003). Transaction cost framework in operations and supply chain management research: theory and measurement. Journal of Operations Management, 21(4), 457-473.

Gulati, R. (1995). Does familiarity breed trust? The implications of repeated ties for contractual choice in alliances. Academy of Management Journal, 38(1), 85-112. 
Gulati, R. (1998). Alliances and networks. Strategy Management Journal, 19(2), 293-317.

Gulati, R, \& Gargiulo, M. (1999). Where do interorganizational networks come from? American Journal of Sociology, 104(5), 1439-1493.

Gulati, R, Nohria, N, \& Zaheer, A. (2000). Strategic networks. Strategic Management Journal, 21(3), 203-215.

Gulati, R, \& Sytch, M. (2007). Dependence asymmetry and joint dependence in interorganizational relationships: effects of embeddedness on a manufacturer's performance in procurement. Administrative Science Quarterly, 52(1), 32-69.

Hoetker, G, \& Mellewigt, T. (2009). Choice and performance of governance mechanisms: matching alliance governance to asset type. Strategic Management Journal, 30(10), 1025-1044.

Holcomb, T, \& Hitt, M. (2007). Toward a model of strategic outsourcing. Journal of Operations Management, 25(2), 464-481.

Jaccard, J, Torrisi, R, \& Wan, C. K. (1990). Interaction effects in multiple regression. Newbury Park: Sage.

Johnston, D. A, McCutcheon, D. M, Stuart, F. I, \& Kerwood, H. (2004). Effects of supplier trust on performance of cooperative supplier relationships. Journal of Operations Management, 22(1), 23-38.

Jones, C, Hesterly, W. S, \& Borgatti, S. P. (1997). A general theory of network governance: exchange conditions and social mechanisms. Academy of Management Review, 22(4), 911-945.

Kuwabara, K, \& Sheldon, O. (2012). Temporal dynamics of social exchange and the development of solidarity: "testing the waters" versus "taking a leap of faith". Social Forces, 91(1), 253-273.

Lado, A. A, Dant, R. R, \& Tekleab, A. G. (2008). Trust-opportunism paradox, relationalism, and performance in interfirm relationships: evidence from the retail industry. Strategic Management Journal, 29(4), 401-423.

Lavie, D. (2006). The competitive advantage of interconnected firms: an extension of the resource-based view. Academy of Management Review, 31(3), 638-658.

Lazzarini, S. G. (2007). The impact of membership in competing alliance constellations: evidence on the operational performance of global airlines. Strategic Management Journal, 28(4), 345-367.

Lazzarini, S. G, Claro, D. P, \& Mesquita, L. F. (2008). Buyer-supplier and supplier-supplier alliances: do they reinforce or undermine one another? Journal of Management Studies, 45(3), 561-584.

Mayer, R. C, Davis, J. H, \& Schoorman, F. D. (1995). An integrative model of organizational trust. Academy of Management Review, 20(3), 709734 .

McEvily, B. (2011). Reorganizing the boundaries of trust: from discrete alternatives to hybrid forms. Organization Science, 22(5), 1266-1276.

McEvily, B, \& Tortoriello, M. (2011). Measuring trust in organizational research: review and recommendations. Journal of Trust Research, 1(1), 23-63.

Mclvor, R. (2000). A practical framework for understanding the outsourcing process. Supply Chain Management: an International Journal, 5(1), 22-36.

North, D. C. (1990). Institutions, institutional change, and economic performance. New York: Cambridge University Press.

Nyaga, G. N, Whipple, J. M, \& Lynch, D. F. (2010). Examining supply chain relationships: do buyer and supplier perspectives on collaborative relationships differ? Journal of Operations Management, 28(2), 101-114.
Pfeffer, J, \& Salancik. G. R. (1978). The external control of organizations: a resource dependence perspective. New York: Harper \& Row.

Podsakoff, P. M, \& Organ, D. W. (1986). Self-reports in organizational research: problems e prospects. Journal of Management, 12 (4), 531-544.

Poppo, L, \& Zenger, T. (2002). Do formal contracts and relational governance function as substitute or complement? Strategic Management Journal, 23(8), 707-725.

Powell, W. W. (1990). Neither market nor hierarchy: network forms of organization. In B. M. Staw, \& L. L. Cummings (Eds.). Research in organizational behavior (Vol. 12, pp. 295-336). Greenwich: JAI Press.

Powell, W. W. (1996). Inter-organizational collaboration in the biotechnology industry. Journal of Institutional and Theoretical Economics, 152(1), 197-225.

Powell, W. W, White, D. R, Koput, K. W, \& Owen-Smith, J. (2005). Network dynamics and field evolution: the growth of interorganizational collaboration in the life sciences. American Journal of Sociology, 110(4), 11321205.

Rangan, S. (2000). The problem of search and deliberation in economic action: when social networks really matter. Academy of Management Review, 25(4), 813-828.

Rempel, J. K, Holmes, J. G, \& Zanna, M. P. (1985). Trust in close relationships. Journal of Personality and Social Psychology, 49(1), 95-112.

Ring, P. S, \& Ven, A. van de (1992). Structuring cooperative relationships between organizations. Strategic Management Journal, 13(7), 483-498.

Rogan, M. (2013). Too close for comfort? The effect of embeddedness and competitive overlap on client relationship retention following an acquisition. Organization Science, 25(1), 185-203.

Rowley, T, Behrens, D, \& Krackhardt, D. (2000). Redundant governance structures: an analysis of structural and relational embeddedness in the steel and semiconductor industries. Strategic Management Journal, 21(3), 369-386.

Rungtusanatham, M. J, Choi T. Y, Hollingworth, D. G, Wu, Z, \& Forza, C. (2003). Survey research in operations management: historical analyses. Journal of Operations Management, 21(4), 475-488.

Shipilov, A. V. (2005). Should you bank on your network? Relational and positional embeddedness in the making of financial capital. Strategic Organization, 3(3), 279-309.

Slack, N, Chambers, S, Harland, C, Harrison, A, \& Johnson, R. (1998). Operations management (2nd ed.). London: Pitman Publishing.

Stikin, S. B. (1995). On the positive effect of legalization on trust. In R. J. Bies, R. J. Lewicki, \& B. H. Sheppard. Research on negotiation in organization (Vol. 4, pp. 367-392). Greenwich: Jai Press.

Uzzi, B. (1996). The sources and consequences of embeddedness for the economic performance of organizations: the network effect. American Sociological Review, 61(4), 674-698.

Uzzi, B. (1997). Social structure and competition in interfirm networks: the paradox of embeddedness. Administrative Science Quarterly, 42(1), $35-67$.

Uzzi, B. (1999). Embeddedness in the making of financial capital: how social relations and networks benefit firms seeking financing. American Sociological Review, 64(4), 481-505.

Uzzi, B, \& Gillespie, J. (1999). Corporate social capital and the cost of financial capital: an embeddedness approach. In J. Lenders, \& S. Gabbay (Eds.). Corporate social capital (pp. 446-459). New York: Kluwer. 
Uzzi, B, \& Lancaster, R. (2004). Embeddedness and price formation in the corporate law market. American Sociological Review, 69(3), 319-344.

Vasconcelos, G. M. R, \& Oliveira, J. L. (2012). Imersão social e institucional e capacidades: o setor calçadista de Nova Serrana. RAE-Revista de Administração de Empresas, 52(5), 531-545.

Villena, V. H, Revilla, E, \& Choi, T. Y. (2011). The dark side of buyer-supplier relationships: a social capital perspective. Journal of Operations Management, 29(6), 561-576.

Wernerfelt, B. (1995). The resource-based view of the firm: ten years after. Strategic Management Journal, 16(3), 171-174.
Williamson, O. E. (1975). Markets and hierarchies. New York: Free Press.

Zaheer, A, McEvily, B, \& Perrone, V. (1998). Does trust matter? Exploring the effects of interorganizational and interpersonal trust on performance. Organization Science, 9(2), 141-159.

Zajac E. J, \& Olsen, C. P. (1993). From transaction cost to transactional value analysis: implications for the study of interorganizational strategies. Journal of Management Studies, 30(1), 131-145.

Zukin, S, \& Dimaggio, P. (1990). Structures of capital: the social organization of the economy. Cambridge: Cambridge University Press. 